\title{
Temporal Variation of Culture Independent Bacterial Diversity Based on Amplicon Sequencing of the North Sikkim Hot Spring Solfataric Soil Sediments
}

\author{
Sayak Das \\ Sikkim University \\ Mingma Thundu Sherpa \\ Sikkim University \\ Ishfaq Nabi Najar \\ Sikkim University \\ Ankita Kumari \\ Sikkim University \\ Nagendra Thakur ( $\nabla$ nthakur@cus.ac.in ) \\ Sikkim University https://orcid.org/0000-0001-8384-6586
}

\section{Research Article}

Keywords: geothermal system, thermophiles, soil microflora, Sikkim Himalayas

Posted Date: November 9th, 2021

DOI: https://doi.org/10.21203/rs.3.rs-1002781/v1

License: (c) (i) This work is licensed under a Creative Commons Attribution 4.0 International License. Read Full License 


\section{Abstract}

The solfataric soil sediments of the hot springs of Sikkim located at Yume Samdung and Lachen valley were studied for deciphering the uncultured bacterial diversity. The main aim here is to present a comparative study and generate a baseline data on the post-monsoon seasonal variation for the months of October and December, analysed through 16S rRNA V3-V4 amplicon sequencing. At phylum level, in the New Yume Samdung (NYS) hot spring soil sample, in the month of October it was dominated by Proteobacteria $(21.03 \%)$ followed by Thermi (12.33\%) and Bacteroidetes (9.95\%) whereas in December it was dominated by Proteobacteria (23.61\%) followed by Chloroflexi (19.15\%) and Bacteroidetes (16.55\%). For Old Yume Samdung (OYS) hot spring soil sample, in the month of October, it was dominated by Proteobacteria (25.22\%) followed by Bacteroidetes (11.76\%) and Thermi (8.11\%) whereas in December it was dominated by Proteobacteria (20.58\%) followed by Chloroflexi (18.88\%) and Thermi (9.89\%). And in the case of Tarum (TAR) hot spring soil sediments, in the month of October, it was dominated by Proteobacteria (27.51\%) followed by Bacteroidetes $(12.29 \%)$ and Actinobacteria $(11.1 \%)$ whereas in December it was dominated by Proteobacteria (16.76\%) followed by Bacteroidetes (16.54\%) and Thermi (14.17\%). At genus level, in NYS, in October it was dominated by Meiothermus (12.33\%) and in December it was Roseiflexus (8.59\%). For OYS, it was dominated by Meiothermus (8.11\%) in October and by unclassified Chloroflexales (10.94\%) in December. And in TAR, it was dominated by unclassified Bacteroidales (10.29\%) in October and by Meiothermus $(14.12 \%)$ in December.

\section{Introduction}

The most prodigious gift of Nature if anyone has to consider, then undoubtedly it has to be the extreme environmental conditions. The word "extreme" has been concocted by the mankind as the abiotic parameters governing these niches or ecosystem is beyond human adaptive physiological capabilities. Our cognitive functioning and metabolomics cannot explain or survive the ruthlessness of nature's extreme ecosystems be it on the basis of temperature or $\mathrm{pH}$ or salinity or atmospheric pressure. The countenance of hot springs is their invaluable micro flora and fauna which has gained impetus in recent decades [1]. The hot spring microbiology is regarded as the hotspot of research in the arena of microbial ecology as study of life at extremes has challenged the scientific world to retrospect the adaptability and limitations of life [2]. Encountering the limitations from culture dependent methods, new molecular strategies such as amplicon/shotgun sequencing, nanopore chip assay, omic tools etc. gave a leapfrog advantage for better understanding of the microbial diversity throughout the world [3]. Aiming the geomicrobiological features, microbial community structure of different geothermal springs has been determined worldwide such as in China [4], Japan [5], South Africa, Colombia, solfataric fields of Iceland, Great Basin hot springs, and Yellowstone National Park (USA) [6, 7]. The Indian sub-continent supposedly houses 400 hot springs distributed across seven geothermal provinces and among them only about 30 hot springs have been explored with respect to microbiological aspects [8]. And out of these 30 hot springs, the hot spring soil ecology and their bacterial diversity analysed through High Throughput Sequencing (HTS) have been limited and covers only the hot springs of Manikarnan (Himachal Pradesh), Tapovan (Uttarakhand), Jakrem (Meghalaya) and Taptopani and, Atri (Orissa). Most of the researches have been on the hot spring water only, and so far, there are no studies on the seasonal variation of the microbial diversity in these geothermal systems. Hence, the bacterial diversity analysis of the hot spring encompassing both the soil and water components are of great significance, as these hot springs have been traditionally used for various balneotherapeutic purposes and recreational activities [9].

On the context of the soil microflora studies of the hot springs of Sikkim, there is a dearth in the knowledge of its ecology and diversity. Here, we have tried to examine the hot spring soil bacterial ecology to understand its 
community structure through culture-independent approach. An attempt was done to generate a first-ever report on the monthly variation in these diversity profiles during the post-monsoon season at Sikkim Himalayas.

\section{Materials And Methods}

\section{Sampling Sites and sample collection}

The geographical position of the coordinates and elevation (above mean sea level) of the hot springs were measured with the help of GPSMAP 78S (Garmin, India). The hot springs located at the North Sikkim district were selected for the current study (Figure 1). Three hot spring soil samples were chosen for the present study - NYS, OYS and TAR. NYS (New Yume Samdung) hot spring is situated at an altitude of $4685.8 \mathrm{~m}$ above the mean sea level at $27.917302^{\circ} \mathrm{N}$ and $88.694308^{\circ} \mathrm{E}$ coordinates. OYS (Old Yume Samdung) hot spring lies just beside the NYS within few meters away. It is situated at an altitude of $4687.9 \mathrm{~m}$ above the mean sea level at $27.918242^{\circ} \mathrm{N}$ and $88.694935^{\circ} \mathrm{E}$ coordinates. Both the hot springs are situated at the Yume Samdung valley. The third hot spring, Tarum/Takrum Tsha Chuu (TAR) is located at Tarum valley, Lachen. It is also known as Lha Bha Tarum Tsha Chuu. It is located at $2893 \mathrm{~m}$ above the mean sea level at $27.703888^{\circ} \mathrm{N}$ and $88.575277^{\circ} \mathrm{E}$ coordinates. In local dialect, hot springs are referred to as the "Tsha Chuu/Tatopani" [9]. The temperature of NYS, OYS and TAR hot spring soil, during the month of October was around $57^{\circ} \mathrm{C}, 45^{\circ} \mathrm{C}$, and $44^{\circ} \mathrm{C}$ that increased to $61^{\circ} \mathrm{C}, 57^{\circ} \mathrm{C}$, and $49^{\circ} \mathrm{C}$ during the month of December respectively. Similarly, in the case of $\mathrm{pH}$, at NYS, OYS and TAR, they were moderately alkaline in the month of October, ranging from 8.5 to 9.2, whereas during the month of December, with decrease in the groundwater aquifer discharges, it got reduced to 7.8-9 (Table 1). Thus, it can be said that there was variations in temperature and $\mathrm{pH}$ observed in these hot spring soil components.

Table 1

GPS mapping coordinates and in-situ data of the sampling sites

\begin{tabular}{|c|c|c|c|c|c|c|c|}
\hline \multirow{2}{*}{$\begin{array}{l}\text { Hot } \\
\text { Springs }\end{array}$} & \multirow[t]{2}{*}{ Latitude } & \multirow[t]{2}{*}{ Longitude } & \multirow{2}{*}{$\begin{array}{l}\text { Elevation } \\
\text { (a.m.s.l) }\end{array}$} & \multicolumn{2}{|c|}{ Soil Temperature* } & \multicolumn{2}{|c|}{ Soil pH* } \\
\hline & & & & OCT & DEC & OCT & DEC \\
\hline NYS & $27.917302^{\circ}$ & $\begin{array}{l}88.694308^{\circ} \\
E\end{array}$ & $\begin{array}{l}4685.8 \\
\mathrm{~m}\end{array}$ & $\begin{array}{l}57.71^{\circ} \mathrm{C} \pm \\
0.050\end{array}$ & $\begin{array}{l}61.47^{\circ} \mathrm{C} \pm \\
0.345\end{array}$ & $\begin{array}{l}8.76 \pm \\
0.078\end{array}$ & $\begin{array}{l}8.59 \pm \\
0.141\end{array}$ \\
\hline OYS & $27.918242^{\circ}$ & $\begin{array}{l}88.694935^{\circ} \\
\mathrm{E}\end{array}$ & $\begin{array}{l}4687.9 \\
\mathrm{~m}\end{array}$ & $\begin{array}{l}45.52^{\circ} \mathrm{C} \pm \\
0.123\end{array}$ & $\begin{array}{l}57.71^{\circ} \mathrm{C} \pm \\
0.05\end{array}$ & $\begin{array}{l}9.17 \pm \\
0.04\end{array}$ & $\begin{array}{l}9.042 \pm \\
0.097\end{array}$ \\
\hline TAR & $27.703888^{\circ}$ & $\begin{array}{l}88.575277^{\circ} \\
E\end{array}$ & $2843 \mathrm{~m}$ & $\begin{array}{l}44.26^{\circ} \mathrm{C} \pm \\
0.083\end{array}$ & $\begin{array}{l}49.61^{\circ} \mathrm{C} \pm \\
0.374\end{array}$ & $\begin{array}{l}8.46 \pm \\
0.020\end{array}$ & $\begin{array}{l}7.8 \pm \\
0.022\end{array}$ \\
\hline
\end{tabular}

The solfataric soil sediments $(1000 \mathrm{gm})$ were aseptically pooled in triplicates from different sections encompassing the whole perimeter of the NYS, OYS, and TAR hot springs of North Sikkim district in sterile sample containers [10]. The samples were preserved in-situ by storing in the thermally insulated sampling box packed with ice gel bags and were then transported (temperature maintained at $4^{\circ} \mathrm{C}$ ) for DNA extraction analysis.

\section{Environmental Dna Isolation And Quantitative Analysis}

The environmental DNA (eDNA) was extracted using NucleoSpin Soil Kit (MACHEREY-NAGEL GmbH and Co. KG, Dueren, Germany) in accordance with the manufacturer's protocol. The eDNA extraction and the amplicon 
sequencing were done at Eurofins Pvt. Ltd., Bangalore. Quality of the DNA was checked on 0.8\% agarose gel and quantified using Qubit Fluorometer (Thermofisher Scientific, USA), with a detection limit of $10-100 \mathrm{ng} . \mathrm{\mu L}^{-1}$.

\section{6s Rrna Amplicon Sequencing Library Preparation}

Amplifications of the V3 and V4 regions of bacterial 16S rRNA gene were done using two primers 16S rRNA-F5'GCCTACGGGNGGCWGCAG3' and 16S rRNA-R-5'ACTACHVGGGTATCTAATCC3' [11]. The amplicon libraries were prepared using Nextera XT Index Kit (Illumina Inc.), in accordance with the $16 \mathrm{~S}$ metagenomic sequencing library preparation protocol [12]. The amplicon library was purified with AMPure XP beads. The amplified libraries were analyzed on 4200 Tape Station system (Agilent Technologies) using D1000 Screen tape as per manufacturer instructions and the concentration was quantified by Qubit Fluorometer. Based on the data obtained from the Qubit Fluorometer and the Bioanalyzer, $500 \mathrm{uL}$ of the $10 \mathrm{pM}$ library was loaded into MiSeq cartridge for cluster generation and sequencing. Paired-end sequencing method (read length 2 X 300bp) was used. After the sequencing, highquality metagenome reads were trimmed to remove the barcode and adaptor sequences.

\section{Data And Statistical Analysis}

Samples (NYS_MUD_OCT, NYS_MUD_DEC, OYS_MUD_OCT, OYS_MUD_DEC, TAR_MUD_OCT, and TAR_MUD_DEC) were subjected to pre-processing of reads, de-replication, singleton removal, OTU clustering, chimera filtering and each OTUs annotation till species level, with QIIME2 release 2020.6 [13]. For quality control of the sequences, the DADA2 plugin in Qiime 2 was used to associate erroneous sequence reads with the true biological sequence from which they were derived, thus producing high-quality sequence variant data. Using DADA2, all reads were trimmed to $260 \mathrm{bp}$, based on the median quality score. In addition, chimeric sequences were detected and excluded from analyses. 16S rRNA OTUs were picked using a closed-reference OTU picking protocol against the Greengenes database (https:// data.qiime2.org/2020.6/common/gg-13-8-99-515-806-nb-classifier.qza) In the next step, taxonomy assignments were associated with OTUs based on the taxonomy associated with the Greengenes reference sequence defining each OTU [14]. The taxonomic abundance at several levels was classified - kingdom, phylum, class, order, family, genus and species. Sequences without homologous pair were classified as unknown. Statistical analysis based on PERMANOVA in OTUs composition between the six samples was done. Venn diagram and correlation matrix was used to depict the variation among the OTUs.

\section{Results}

\section{Diversity Indices and Rarefaction Curves}

Rarefaction curve plots the number of species as a function of the number of samples (Figure 2). Also, other indices were calculated to show the species richness in the hot spring soil sediments (Supplementary Table ST1). There was considerable variation in both the phylum and genus level at all the indices for the month of October and December (Supplementary Figure SF1). Highest Shannon Index was observed in sample OYS for the month of December and lowest was in the case of Tarum (December) at both the phylum and genus level diversity.

\section{Phylum Level Bacterial Diversity}


Proteobacteria, Thermi, Bacteroidetes, Firmicutes, Chloroflexi, Planctomycetes, Acidobacteria, Actinobacteria, Spirochaetes, Candidate phylum OD1 (Parcubacteria) and Nitrospirae were the major abundant phylum present in all the solfataric soil sediments of the studied hot spring ecosystem of Sikkim (Figure 3). There was a considerable amount of variation in their abundance percentages when observed individually.

The NYS hot spring had Proteobacteria as the most dominant phyla in both the months of October (21.03\%) and December $(23.61 \%)$ in the post-monsoon season. At individual level of phylum diversity, in NYS, it was abundant in Thermi, Bacteroidetes, Firmicutes, Chloroflexi, Planctomycetes, Acidobacteria, Actinobacteria, Spirochaetes, candidate phylum OD1 and Nitrospirae. Interestingly, on comparing the relative variation among these phylum during the two months, it was observed that, with the onset of heavy winters and snowfall, during the month of December, the abundance percentage of Thermi (Oct-12.33\%; Dec-8.18\%), Firmicutes (Oct-9.07\%; Dec-5.3\%), Planctomycetes (Oct-7.67\%; Dec-3.49\%), Acidobacteria (Oct-4.41\%; Dec-3.28\%) and Actinobacteria (Oct-2.52\%; Dec$0.51 \%$ ) decreased drastically. Whereas, Proteobacteria (Oct-21.03\%; Dec-23.61\%), Bacteriodetes (Oct-9.95\%; Dec16.55\%), Chloroflexi (Oct-8.25\%; Dec-19.15\%), Spirochaetes (Oct-2.35\%; Dec-5.11\%), candidate phylum OD1 (Oct1.39\%; Dec-5.16\%) and Nitrospirae (Oct-0.5\%; Dec-2.89\%) increased in relative abundance.

In OYS hot spring, on comparing the relative abundance percentage, it was observed that Proteobacteria (Oct25.22\%; Dec-20.58\%), Bacteroidetes (Oct-11.76\%; Dec-5.59\%), Firmicutes (Oct-4.56\%; Dec-1.5\%), Nitrospirae (Oct2.44\%; Dec-0.75\%), Actinobacteria (Oct-2.26\%; Dec-1.79\%) and Chlorobi (Oct-1.84\%; Dec-0.97\%) decreased gradually with the onset of winters in the month of December. Whereas, Thermi (Oct-8.11\%; Dec-9.89\%), Chloroflexi (Oct-8.1\%; Dec-18.88\%), and Acidobacteria (Oct-2.93\%; Dec-4.99\%), increased comparatively in relative abundance from the month of October. Interestingly, Planctomycetes (Oct-4.51\%; Dec-4.8\%) had no relative change in the abundance on comparing both the months. Also, candidate phylum OP8 which was absent during the month of October was observed in the month of December in the sample. Thus, it can be said, the winter climate favored its ecological growth.

In TAR hot spring, on comparing the relative abundance percentage, it was observed that Proteobacteria (Oct27.51\%; Dec-16.77\%), Actinobacteria (Oct-11.1\%; Dec-1.65\%), candidate TM7 (Oct-1.23\%; Dec-<0.01\%) and Verrucomicrobia (Oct-4.81\%; Dec-0.28\%) decreased considerably with the onset of winters in the month of December. Whereas, Bacteroidetes (Oct-12.29\%; Dec-16.54\%), Planctomycetes (Oct-6.88\%; Dec-9.07\%), Acidobacteria (Oct-4.44\%; Dec-8.69\%), Chlorobi (Oct-0.94\%; Dec-1.51\%), candidate phylum OD1 (Oct-0.78\%; Dec$6.21 \%$ ), and Spirochaetes (Oct-0.16\%; Dec-2.7\%) increased in relative abundance from the month of October. Chloroflexi (Oct-9.19\%; Dec-9.76\%) and Firmicutes (Oct-4.02\%; Dec-4.37\%) had no relative change in the abundance on comparing both the months. The most fascinating observation was in the case of Thermi. The relative abundance percentage of it was $<0.01 \%$ in the month of October which had a sharp increase of $14.17 \%$ abundance in the month of December with the onset of snowfall. Thus, it can be said, the winter climate favored its ecological growth. Overall, it can also be said that at the phylum level, TAR hot spring had more variation and diversity compared to the other studied hot springs. All the data are tabulated in Supplementary Table ST2.

\section{Genus Level Bacterial Diversity}

The genus level diversity showed more unclassified genera which suggests the possibility of discovering novel genera from these hot spring solfataric soil sediments. Meiothermus, Planctomyces and Thiobacillus, were some of the common genera found and among the unclassified genera, mostly belonged to the order Chloroflexales, 
Bacteriodales and Solibacteriales. There was higher variation among all the individual samples observed during both the months (Figure 4).

The relative variation among these genera during the two months, was observed that, with the onset of heavy winters and snowfall, during the month of December, the abundance percentage of Meiothermus (Oct-12.33\%; Dec8.18\%), unclassified Bacteroidales (Oct-5.55\%; Dec-3.76\%), Planctomyces (Oct-5.06\%; Dec-0.36\%), unclassified Solibacterales (Oct-3.61\%; Dec-2.74\%), unclassified Clostridiales (Oct-3.58\%; Dec-1.17\%), Flavihumibacter (Oct2.89\%; Dec-0.1\%), Rhodoplanes (Oct-2.69\%; Dec-0.1\%), and unclassified Caulobacterales (Oct-2.08\%; Dec-0.02\%) decreased drastically. Whereas, Roseiflexus (Oct-2.48\%; Dec-8.59\%), Treponema (Oct-1.93\%; Dec-2.98\%), Thiobacillus (Oct-1.78\%; Dec-3.27\%), Bellilinea (Oct-1.37\%; Dec-3.31\%), unclassified ABY1 (Oct-1.2\%; Dec-5.07\%), unclassified Chloroflexales (Oct-0.73\%; Dec-5.86\%), and Blvii28 (Oct-0.11\%; Dec-6.71\%) increased in relative abundance. The most interesting observation here was that of Cloacibacterium, which was absent in the month of October but had higher abundance in the month of December (3.09\%). It was also not found in any of the other samples. It seems to be exclusively present in OYS hot spring.

In OYS hot spring, on comparing the relative abundance percentage, it was observed that Thermomonas (Oct-3.36\%; Dec-0.03\%), unclassified Bacteroidales (Oct-7.75\%; Dec-1.54\%), Thiobacillus (Oct-3.28\%; Dec-2.22\%), Flavihumibacter (Oct-2.36\%; Dec-0.16\%), candidate genus LCP-6 (Oct-2.04\%; Dec-0.23\%), unclassified Burkholderiales (Oct-1.7\%; Dec-0.9\%) and Alicyclobacillus (Oct-1.97\%; Dec-0.13\%) decreased gradually with the onset of winters in the month of December. Whereas, Meiothermus (Oct-8.11\%; Dec-9.89\%), unclassified Solibacterales (Oct-2\%; Dec-4.52\%), unclassified Chloroflexales (Oct-1.22\%; Dec-10.94\%), unclassified Syntrophobacterales (Oct-0.46\%; Dec-1.85\%) unclassified Thiobacterales (Oct-0.86\%; Dec-3.45\%) unclassified mle18 (Oct-0.27\%; Dec-2.97\%), candidate genus SHD-231 (Oct-0.03\%; Dec-1.88\%) and unclassified OPB95 (Oct-0.01\%; Dec-1.73\%), increased comparatively in relative abundance from the month of October. Interestingly, genus Bellilinea (Oct-1.3\%; Dec-1.8\%) had no relative change in the abundance on comparing both the months.

In TAR hot spring, on comparing the relative abundance percentage, it was observed that genera belonging to the order from unclassified Bacteroidales (Oct-10.29\%; Dec-4.17\%), unclassified Anaerolineales (Oct-4.72\%; Dec-0.82\%), unclassified Rhizobiales (Oct-3.16\%; Dec-0.4\%), unclassified Gemmatales (Oct-2.21\%; Dec-0.24\%), Rhodoplanes (Oct-2.2\%; Dec-0.21\%), Desulfococcus (Oct-1.9\%; Dec-0.02\%), and unclassified Pedosphaerales (Oct-1.89\%; Dec$0.02 \%$ ) decreased considerably with the onset of winters in the month of December. Whereas, the genera of unclassified Solibacterales (Oct-1.68\%; Dec-7.47\%), Planctomyces (Oct-0.83\%; Dec-6.23\%), Treponema (Oct-0.04\%; Dec-2.61\%), unclassified OD1 (Oct-0.02\%; Dec-4.96\%), Flavobacterium (Oct-0.02\%; Dec-5.75\%), Blvii28 (Oct-0.01\%; Dec-4.87\%), Meiothermus (Oct-<0.01\%; Dec-14.12\%) and unclassified Rhodospirillales (Oct-<0.01\%; Dec-2.56\%) increased in relative abundance from the month of October. Genera belonging to the order unclassified Chloroflexales (Oct-2.19\%; Dec-2.97\%) had no relative change in the abundance on comparing both the months. The most enthralling observation was in the case of genus Dyella (Oct-1.84\%; Dec-nil) and belonging to the order unclassified Actinomycetales (Oct-3.47\%; Dec-nil). They were completely absent in the month of December but were in abundance in the month of October. Thus, it can be said, the winter climate reduced its ecological growth. Overall, it can also be said that at the genus level, TAR hot spring had more variation and unclassified genera diversity compared to the other studied hot springs. All the data are tabulated in Supplementary Table ST3.

\section{Discussion}


In India, the geothermal exploration began in early 1973 by Geological Survey of India and they reported more than 350 hot springs having temperature range varying above $40^{\circ} \mathrm{C}-100^{\circ} \mathrm{C}$ throughout the entire sub-continent region. Based on the tectonic movements, the hot springs of India were categorized into orogenic and non-orogenic [15]. Sikkim naturally hosts many hot springs. It is a major tourist attractive state of India where nature is in its juvenile form and a refreshing season greets its visitors. Previous studies through culture independent studies was done on the water samples from some hot springs of Sikkim located at Polok, Borong, Reshi and Yumthang, showed bacterial diversity at both the phylum and genus levels. Those hot spring water samples, were abundant in Proteobacteria (Polok-47\%; Borong-63\%; Reshi-76\%) and Yumthang hot spring was predominant with Actinomycetes (98\%). The most abundant genera in the hot spring water of Sikkim were Acidovorax, Acinetobacter, Exiguobacterium, Flavobacterium, Ignavibacterium, Paenisporosarcina, Paracoccus, Pseudomonas, Rhodococcus, Serratia, Sulfuritalea, Thermodesulfovibrio, Thermus, and Thiobacillus [16-19].

The high throughput sequencing assembly (Table 2), obtained gave 234612 reads for NYS (October), 209837 reads for NYS (December), 219384 reads for OYS (October), 238388 reads for OYS (December), 231568 reads for TAR (October), and 254002 reads for TAR (December). A total of 3803 OTUs were obtained from the six soil samples, with the minimum length of an OTU being $291 \mathrm{bp}$ and maximum being 492bp. The mean OTU length obtained was 450.3bp. Statistical analysis based on PERMANOVA revealed significant differences in OTUs composition between the six locations (F-value $\left.=3.534, r^{2}=0.469, p<0.1\right)$.

Table 2

Metagenomics assembly data and statistics

\begin{tabular}{|lllllllll|}
\hline Sample-ID & $\begin{array}{l}\text { Input } \\
\text { reads }\end{array}$ & Filtered & $\begin{array}{l}\text { Percentage } \\
\text { of input } \\
\text { passed } \\
\text { filter }\end{array}$ & Denoised & Merged & $\begin{array}{l}\text { Percentage } \\
\text { of input } \\
\text { merged }\end{array}$ & $\begin{array}{l}\text { Non- } \\
\text { chimeric }\end{array}$ & $\begin{array}{l}\text { Percentage } \\
\text { of input } \\
\text { non- } \\
\text { chimeric }\end{array}$ \\
\hline $\begin{array}{l}\text { NYS- } \\
\text { MUD_OCT }\end{array}$ & 234612 & 128171 & 54.63 & 103589 & 77953 & 33.23 & 17301 & 7.37 \\
$\begin{array}{l}\text { NYS- } \\
\text { MUD_DEC }\end{array}$ & 209837 & 64907 & 30.93 & 48754 & 34036 & 16.22 & 9833 & 4.69 \\
\hline $\begin{array}{l}\text { OYS- } \\
\text { MUD_OCT }\end{array}$ & 219384 & 114717 & 52.29 & 95282 & 70813 & 32.28 & 15801 & 7.2 \\
\hline $\begin{array}{l}\text { OYS- } \\
\text { MUD_DEC }\end{array}$ & 238388 & 76214 & 31.97 & 55434 & 36351 & 15.25 & 12592 & 5.28 \\
\hline $\begin{array}{l}\text { TAR- } \\
\text { MUD_OCT }\end{array}$ & 231568 & 124428 & 53.73 & 99576 & 75310 & 32.52 & 19871 & 8.58 \\
\hline $\begin{array}{l}\text { TAR- } \\
\text { MUD_DEC }\end{array}$ & 254002 & 84522 & 33.28 & 65339 & 44825 & 17.65 & 18408 & 7.25 \\
\hline
\end{tabular}

Venn diagram analysis was done to understand the distribution of shared OTUs at phylum and genus level of the hot spring soil bacterial diversity (Figure 5). Less proportions of OTU were shared between the six hot springs (17 at phylum level and 8 at genus level). The distribution of shared OTUs across the sediments revealed less overlap among each other. Thus, it showed higher variation and diversity among the samples. Box-plot analysis for comparing the alpha diversity indices and Chao 1 values, for the month of October vs. December, among all the hot spring soil sediments, higher species variedness and species richness was obtained in the month of December both at phylum and genus level (Supplementary Figure SF1). Alpha diversity denotes the species variedness and Chao 
value depicts the species richness among the environmental samples. As, the monsoon season is from the month of June to September, at the Sikkim Himalayas, hence during the first month of the post-monsoon season i.e. in October, there is immense diversity of the species in the hot spring soil ecosystem. This might be due to the fact that during rain in these high altitudes, frequent geomorphological changes occurs that enhances the bacterial diversity. Also, with heavy rainfall, the aquifers discharge is substantially high and hence more enrichment of the bacterial ecology occurs. With the recede in rainfall, during the later stages of post-monsoon, i.e., from November onwards these high altitudes starts experiencing snowfall and winter onsets. Thus, with less groundwater aquifer discharge, and also drastic change in the atmospheric conditions, the bacterial diversity at the month of December changes, which is evident from the box-plot.

Hot spring soil ecology is usually governed by complex uncultured bacteriomes. The hot spring soil ecology of the Sikkim Himalayas, had higher percentages of Gram negative bacterial phylum such as Proteobacteria and Bacteroidetes as compared to that of Gram positive bacterial phylum of Firmicutes and Actinobacteria. Interestingly, in the hot spring water samples also similar observations were reported $[16,17,19]$. The resident signature soil flora such as Planctomycetes and Chlorobi, which are commonly found in sulfur rich hot springs were also found here. Photosynthetic flora of Chlorobi was also prevalent in these hot spring soil samples. Temperature plays a very crucial role in the diversity [20]. During the month of December, there were drastic changes in the abundance percentage for majority of the phylum and genera as compared to that from the month of October. At phylum level, the abundance of majority of the phyla such as Proteobacteria, Thermi, Bacteroidetes, Acidobacteria, Planctomycetes, Actinobacteria, Candidate Phylum OP8, Firmicutes and Chlorobi, decreased during the month of December except Chloroflexi (Supplementary Figure SF2) and at genus level, except some unclassified Bacteroidales all the other major genera had higher abundance percentage increase in December (Supplementary Figure SF3). In the various other hot spring soil sediments also, similar observation was found. The hot spring soil of Atri, Bor Khleung, NYS, and Eritrea all had similar range of temperature varying from $50^{\circ} \mathrm{C}$ to $70^{\circ} \mathrm{C}$. The Atri hot spring soil of Orissa and Solfatara Crater, Italy as studied by Sahoo et al. (2015) and Crognale et al. $(2018)$ [21, 22] had the highest abundance of Chloroflexi (52\%; $26 \%$ ) and they lied within the same temperature ranging from $45^{\circ} \mathrm{C}$ to $65^{\circ} \mathrm{C}$. Globally, the hot spring soils are rich in Proteobacteria which seems a common characteristic feature in soil ecology. Bacteriodetes was also relevantly abundant in Taptapani, Bor Khleung, NYS, OYS and TAR. Our findings on Planctomycetes and Verrucomicrobia abundance (5\%-8\%) was similar to that in Eritrea and Bor Khleung samples. Jakrem and Tapovan was the only hot spring soil which was highly robust with Thermi and Firmicutes $[3,18]$. Global comparisons with the various resident soil phylum, the studied hot spring soils of Sikkim had lower abundance percentage of Chloroflexi, Nitrospirae, Proteobacteria and Firmicutes and it was rich in Thermi, Actinobacteria Planctomycetes and Verrucomicrobia.

The hot springs of North-east India i.e. from Sikkim (NYS, OYS and TAR) and Meghalaya (Jakrem) was highly abundant in Thiobacillus, Chloroflexus and Sulfuritalea whereas Eritrea had completely different genera in higher percentages such as Proteiniphilium and Proteiniclasticum [23] which were not reported from Indian Himalaya geothermal regions. Tapovan of Uttarakhand had lower abundance of Flavobacterium, Meiothermus and Acinetobacter [3] which were in higher percentages at Sikkim hot spring soil. At Solfatara Crater, it was predominant with Acidithiobacillus, Sulfobacillus and Leptospirillum [22].

The variation of the genera and phylum depends on various abiotic parameters such as $\mathrm{pH}$, temperature, dissolved oxygen and other physic-chemical components present in the hot springs. Taking them as unity factor, EdgeR and DESEQ2 was performed for calculating the differential abundance analysis. Many low abundance classes or ranks, get omitted during computation. Thus, these statistical tools were used to eliminate this discrimination. 
Thiobacillus, Planctomyces and Arthronema and phylum Cyanobacteria, Acidobacteria, and Armatimonadetes had the highest variation/fluctuations in their relative abundance percentage in NYS, OYS and TAR, throughout both the months (Figure 6). This may be due to the change in temperature $[10,20,24]$ and as well as the variability of ground aquifer discharge with the onset of winter during the post-monsoon season. Meiothermus, Sulfuritalea, Desulfobulbus and Azosprilum, and phylum Thermi, Firmicutes and Bacteroidetes could easily withstand these climatic variations and did not had much effect on their relative abundance percentage. This might be due to their physiological and cellular adaptation to the geothermal environment.

Correlation matrix represented through heat map analysis (Figure 7) was done to compare the unculturable bacterial diversity present in soil among the nine different hot springs of the world - Atri $\left(55^{\circ} \mathrm{C}-58^{\circ} \mathrm{C}\right)$ and Taptani $\left(45^{\circ} \mathrm{C}-50^{\circ} \mathrm{C}\right)$ (Orissa, India), Eritrea $\left(50^{\circ} \mathrm{C}-80^{\circ} \mathrm{C}\right)$, Solfatara Crater $\left(40^{\circ} \mathrm{C}-70^{\circ} \mathrm{C}\right.$, Pozzuoli, Italy), Bor Khlueng $\left(50^{\circ} \mathrm{C}-58^{\circ} \mathrm{C}\right.$, Thailand), Jakrem $\left(45^{\circ} \mathrm{C}-48^{\circ} \mathrm{C}\right.$, Meghalaya, India), New Yume Samdung (NYS) $\left(57^{\circ} \mathrm{C}-61^{\circ} \mathrm{C}\right)$, Old Yume Samdung (OYS) $\left(45^{\circ} \mathrm{C}-57^{\circ} \mathrm{C}\right)$ and Tarum $(\mathrm{TAR})\left(44^{\circ} \mathrm{C}-49^{\circ} \mathrm{C}\right)($ Sikkim, India). The phylum Proteobacteria, Planctomycetes, Bacteroidetes, Chloroflexi, Actinobacteria and Verrucomicrobia were positively correlated and had similar abundance percentages in these hot spring soil sediments as reported by various researchers $[18,19,21-23,25]$. These phyla are commonly associated with the soil flora and are an important contributors of bacterial diversity in the hot springs worldwide. The hot spring soil sediments of Manikarnan (Himachal Pradesh, India), as reported by Mahato et al. (2019), [26] was abundant in Acidothermus, Alishewanella, Arthrobacter, Bacillus, Bifidobacterium, Brevundimonas, Burkholderia, Chloroflexus, Frankia, Meiothermus, Nocardia, Rhodothermus, Thermobaculum, and Thermosynechococcus. And in the studied hot springs of Sikkim, we found majority of the genera present were Thiobacillus, Roseiflexus, Meiothermus, Planctomyces etc. In other hot springs also, there were various genera but mostly belonged to Proteobacteria. Another important aspect was the discovery of many unclassified genera, which suggests that novel flora might be habituating these hot springs.

\section{Conclusion}

In this first ever report on the monthly comparative study of the bacterial diversity from hot spring soil of Sikkim Himalayas during the post-monsoon season, there was remarkable changes in the bacterial diversity both at phylum and genus level. Although only very few studies have been done on the seasonal variation of hot spring soil bacteriomes, a general trend was found common between the available reports globally. Proteobacteria and Bacteriodetes were the worldwide abundant phylum. In case of genera, the Himalayan Geothermal Belt had comparably similar profile, with the abundance of Thiobacillus, Chloroflexus, and Meiothermus whereas other hot springs of Europe and Africa had varied genera owing to their geological difference. Also, it is evident that temperature difference plays a very crucial role in determining the bacterial diversity. With the drop in temperature about $5^{\circ} \mathrm{C}-7^{\circ} \mathrm{C}$ on an average, from the month of October to December, a huge variation of species occurs in the studied Sikkim Himalayan hot spring soil niches. Future studies on the pre-monsoon seasonal variation of the bacterial diversity will complete this initiative and present us with a prismatic view of the complete annual uncultured bacteriome profile. These type of comparative analysis is the result of high throughput sequencing and it helps in understanding these extreme ecologies where the habitats are fragile and are at risk from geomorphological hazards.

\section{Declarations}

\section{Author Contributions}


Sayak Das: Conceptualization, Field Investigation, Methodology, Writing- Original draft preparation, Data Curation, Data Analysis. Mingma Thundu Sherpa: Field Investigation. Ishfaq Nabi Najar: Field Investigation. Nagendra Thakur: Writing - Review \& Editing, Visualization, Supervision.

\section{Funding}

The work was funded by Department of Biotechnology, Ministry of Science and Technology, Government of India (BT/PR25092/NER/95/1009/2017).

\section{Data availability}

Raw amplicon reads were submitted to Sequence Read Archive (SRA), NCBI to obtain the Bio-Project and BioSample accession numbers. Bio-Project accession obtained for the OYS data (October) is PRJNA657139 and BioSample accession is SAMN15815942. Bio-Project accession obtained for NYS data (October) is PRJNA657122 and Bio-Sample accession is SAMN15815778. Bio-Project accession obtained for TAR data (October) is PRJNA657152 and Bio-Sample accession is SAMN15816493. Bio-Project accession obtained for OYS data (December) is PRJNA657147 and Bio-Sample accession is SAMN15816305. Bio-Project accession obtained for NYS data (December) is PRJNA657133 and Bio-Sample accession is SAMN15815908. Bio-Project accession obtained for TAR data (December) is PRJNA657154 and Bio-Sample accession is SAMN15816931.

\section{Code availability}

Not applicable

\section{Declarations}

\section{Ethics approval and}

Not applicable

\section{Consent to participate:}

Not applicable.

\section{Consent for publication}

Not applicable.

\section{Conflict of Interest}

The authors declare that they have no competing interests.

SD would like to thank DST INPIRE, Department of Science and Technology, Govt. of India, for providing the INSPIRE FELLOWSHIP (IF130091) for research work. The authors heartily thank and express their most sincere gratitude to Forest, Environment and Wildlife Management Department, Govt. of Sikkim, Sikkim Police and North Sikkim administration, for granting research permission, kind cooperation and support during the field work. The amplicon sequencing was carried out at Eurofins Pvt. Ltd. and the authors acknowledge them. 


\section{References}

1. Pedron R, Esposito A, Bianconi I et al (2019) Genomic and metagenomic insights into the microbial community of a thermal spring. Microbiome 7:8. https://doi.org/10.1186/s40168-019-0625-6

2. Schmid AK, Allers T, Di Ruggiero J (2020) SnapShot: Microbial Extremophiles. Cell 180(4):818. 818.e1 https://doi.org/10.1016/j.cell.2020.01.018

3. Rawat N, Joshi GK (2019) Bacterial community structure analysis of a hot spring soil by next generation sequencing of ribosomal RNA. Genomics 111(5):1053-1058. https://doi.org/10.1016/j.ygeno.2018.06.008

4. Guo L, Wang G, Sheng Y et al (2020) Temperature governs the distribution of hot spring microbial community in three hydrothermal fields, Eastern Tibetan Plateau Geothermal Belt, Western China. Sci Total Environ 720:137574. https://doi.org/10.1016/j.scitotenv.2020.137574

5. Martinez JN, Nishihara A, Lichtenberg M et al (2019) Vertical distribution and diversity of phototrophic bacteria within a hot spring microbial mat (Nakabusa Hot Springs, Japan). Microbes Environ 34(4):374-387. https://doi.org/10.1264/jsme2.ME19047

6. López-López O, Cerdán ME, González-Siso MI (2013) Hot spring metagenomics. Life (Basel) 3(2):308-320. https://doi.org/10.3390/life3020308

7. Urbieta MS, Donati ER, Chan KG et al (2015) Thermophiles in the genomic era: Biodiversity, science, and applications. Biotechnol Adv 33(6 Pt 1):633-647. https://doi.org/10.1016/j.biotechadv.2015.04.007

8. Poddar A, Das SK (2018) Microbiological studies of hot springs in India: a review. Arch Microbiol 200(1):1-18. https://doi/10.1007/s00203-017-1429-3

9. Das S, Sherpa MT, Sachdeva S et al (2012) Hot springs of Sikkim (Tatopani): a Socio medical conjuncture which amalgamates religion, faith, traditional belief and tourism. Asian Acad Res J Soc Sci Human 1(4):80-93

10. Wang S, Hou W, Dong $\mathrm{H}$ et al (2013) Control of temperature on microbial community structure in hot springs of the Tibetan Plateau. PLoS ONE 8(5):e62901. https://doi.org/10.1371/journal.pone.0062901

11. Klindworth A, Pruesse E, Schweer T et al (2013) Evaluation of general 16S ribosomal RNA gene PCR primers for classical and next-generation sequencing-based diversity studies. Nucleic Acids Res 41(1):e1.

https://doi.org/10.1093/nar/gks808

12. Faircloth BC, Glenn TC, White ND (2014) Illumina library prep protocol Release 2.1.

13. Kuczynski J, Stombaugh J, Walters WA et al (2011) Using QIIME to analyze 16S rRNA gene sequences from microbial communities. Curr Protoc Bioinformatics Chapter 10:Unit.

10.7-10.7

.. https://doi.org/10.1002/0471250953.bi1007s36

14. Edgar RC (2013) UPARSE: highly accurate OTU sequences from microbial amplicon reads. Nat Methods 10(10):996-998. https://doi:10.1038/nmeth.2604

15. Narsing Rao MP, Liu L, Jiao JY et al (2018) Hot springs of India: Occurrence and microbial diversity. In: Egamberdieva D, Birkeland NK, Panosyan H, Li WJ (eds) Extremophiles in Eurasian ecosystems: Ecology, diversity, and applications. Microorganisms for Sustainability, vol 8. Springer, Singapore. https://doi.org/10.1007/978-981-13-0329-6_2

16. Najar IN, Sherpa MT, Das S et al (2018) Microbial ecology of two hot springs of Sikkim: Predominate population and geochemistry. Sci Total Environ 637-638:730-745. https://doi.org/10.1016/j.scitotenv.2018.05.037

Page $11 / 17$ 
17. Najar IN, Sherpa MT, Das S et al (2020) Bacterial diversity and functional metagenomics expounding the diversity of xenobiotics, stress, defense and CRISPR gene ontology providing eco-efficiency to Himalayan Hot Springs. Funct Integr Genomics 20(4):479-496. https://doi.org/10.1007/s10142-019-00723-x

18. Panda AK, Bisht SS, De Mandal S et al (2016) Bacterial and archeal community composition in hot springs from Indo-Burma region, North-east India. AMB Express 6(1):111. https://doi.org/10.1186/s13568-016-0284-y

19. Sharma N, Kumar J, Abedin MM et al (2020) Metagenomics revealing molecular profiling of community structure and metabolic pathways in natural hot springs of the Sikkim Himalaya. BMC Microbiol 20(1):246. https://doi.org/10.1186/s12866-020-01923-3

20. Sharp CE, Brady AL, Sharp GH et al (2014) Humboldt's spa: microbial diversity is controlled by temperature in geothermal environments. ISME J 8(6):1166-1174. https://doi.org/10.1038/ismej.2013.237

21. Sahoo RK, Subudhi E, Kumar M (2015) Investigation of bacterial diversity of hot springs of Odisha, India. Genom Data 6:188-190. https://doi.org/10.1016/j.gdata.2015.09.018

22. Crognale S, Venturi S, Tassi F et al (2018) Microbiome profiling in extremely acidic soils affected by hydrothermal fluids: the case of the Solfatara Crater (Campi Flegrei, southern Italy). FEMS Microbiol Ecol 94(12). https://doi.org/10.1093/femsec/fiy190

23. Ghilamicael AM, Budambula NLM, Anami SE et al (2017) Evaluation of prokaryotic diversity of five hot springs in Eritrea. BMC Microbiol 17(1):203. https://doi.org/10.1186/s12866-017-1113-4

24. Badhai J, Ghosh TS, Das SK (2015) Taxonomic and functional characteristics of microbial communities and their correlation with physicochemical properties of four geothermal springs in Odisha, India. Front Microbiol 6:1166. https://doi.org/10.3389/fmicb.2015.01166

25. Kanokratana P, Chanapan S, Pootanakit K et al (2004) Diversity and abundance of Bacteria and Archaea in the Bor Khlueng Hot Spring in Thailand. J Basic Microbiol 44(6):430-444.

https://doi.org/10.1002/jobm.200410388

26. Mahato NK, Sharma A, Singh Y et al (2019) Comparative metagenomic analyses of a high-altitude Himalayan geothermal spring revealed temperature-constrained habitat-specific microbial community and metabolic dynamics. Arch Microbiol 201(3):377-388. https://doi.org/10.1007/s00203-018-01616-6

\section{Figures}




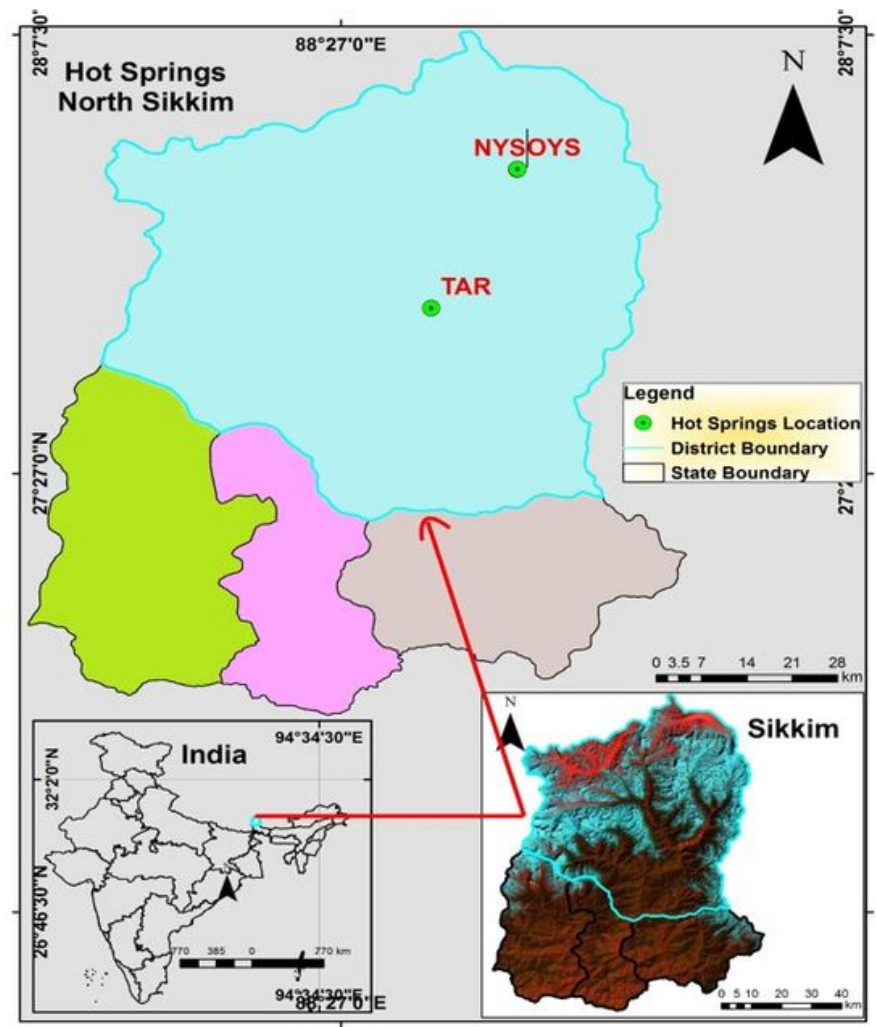

Figure 1: Geographical locations of the sampling sites from where hot spring mud sediments were collected is shown.

\section{Figure 1}

See image above for figure legend

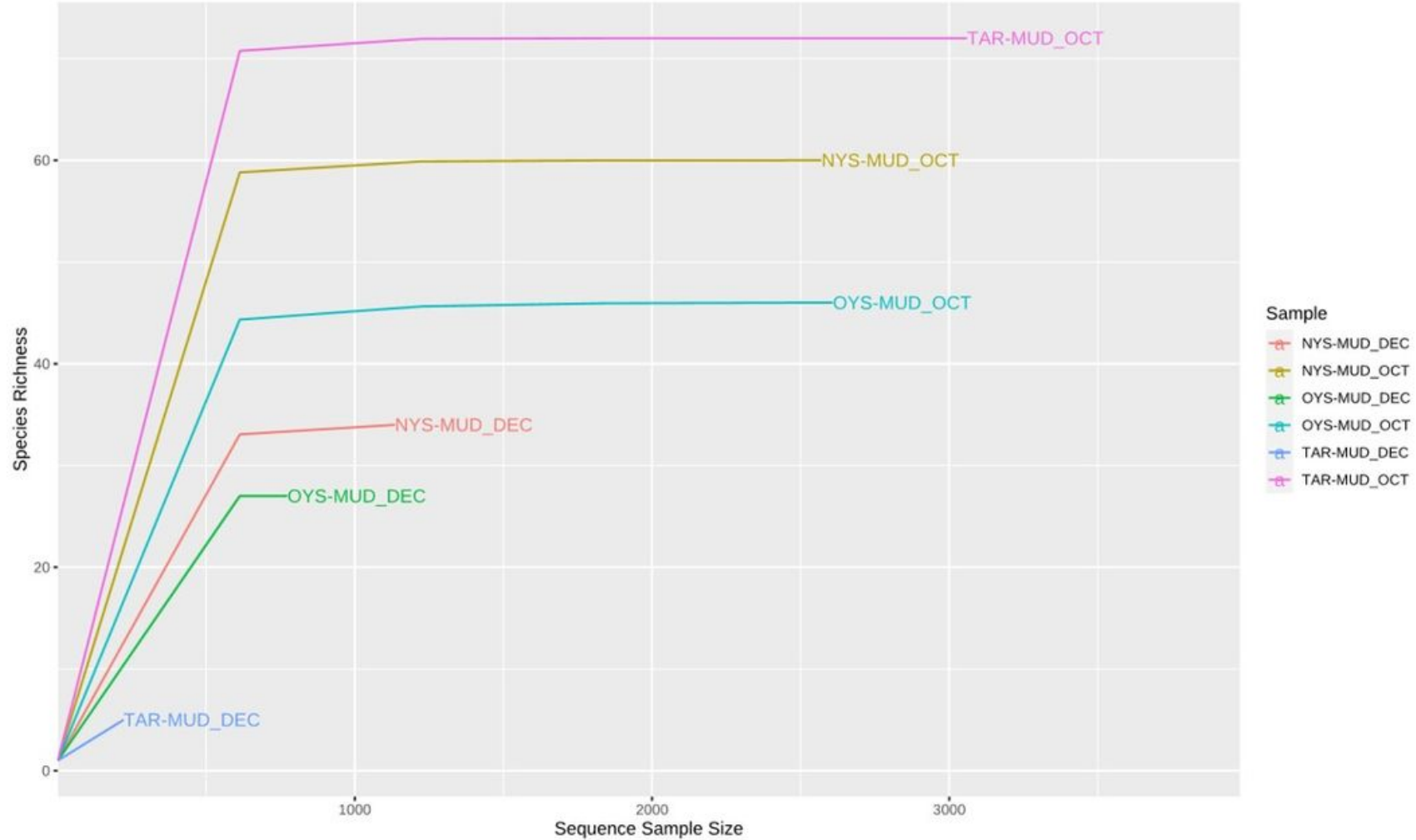

Figure 2: Rarefaction curve showing the species richness in the individual hot spring soil samples.

Figure 2 
See image above for figure legend
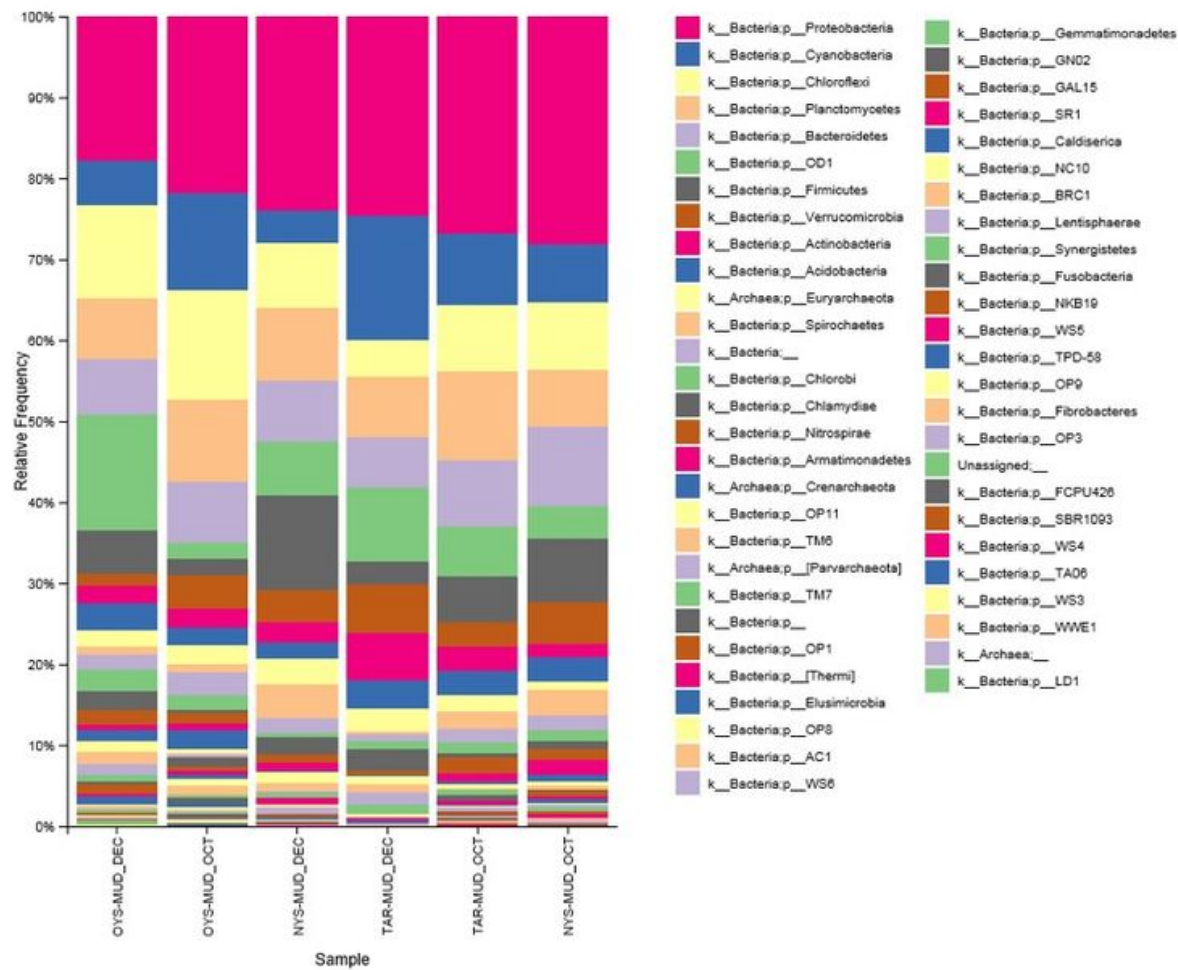

Figure 3: Comparative analysis of the abundant phylum in the soil monthly wise.

\section{Figure 3}

See image above for figure legend
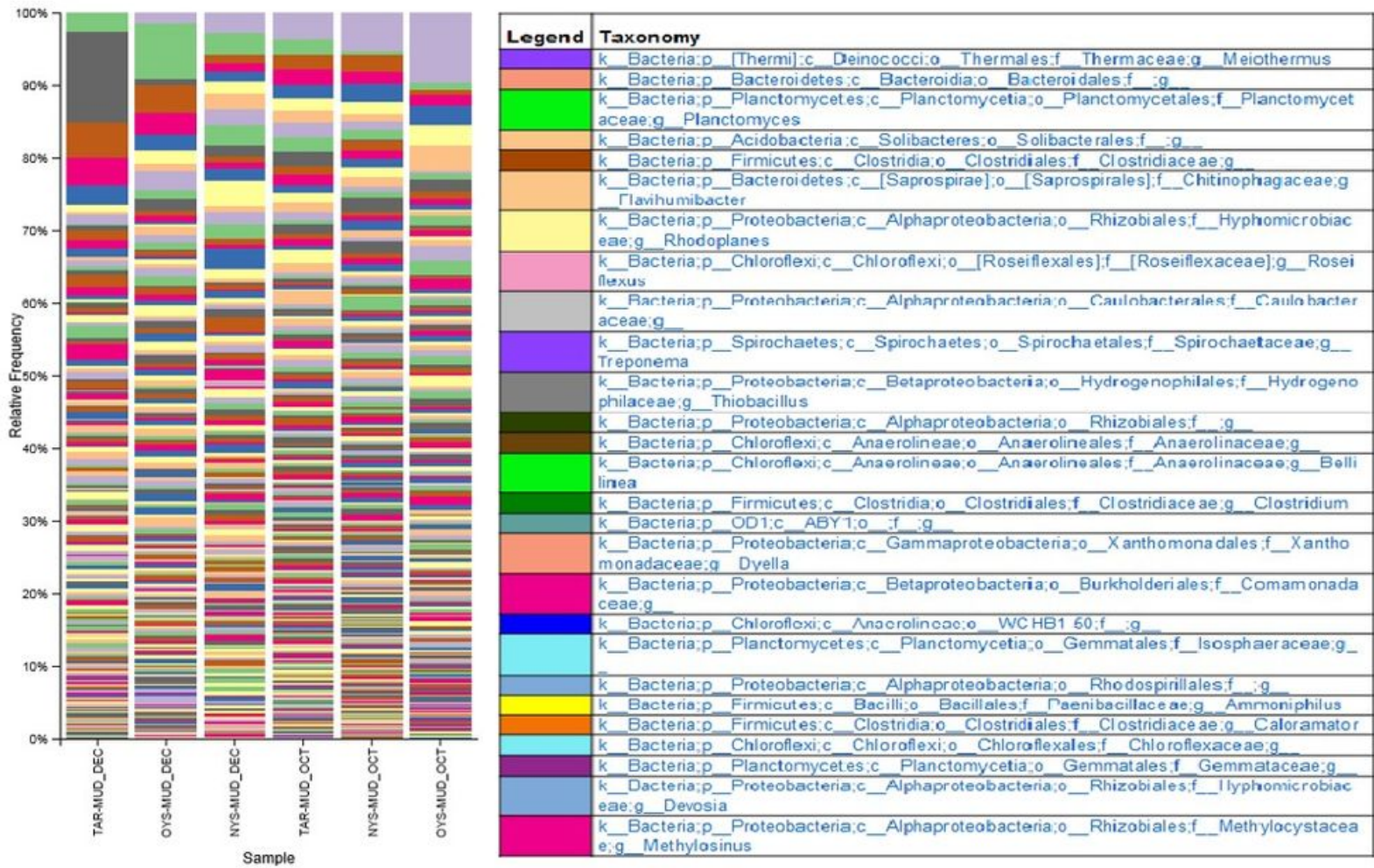

Figure 4: Comparative analysis of the abundant genera in the soil monthly wise. 
Figure 4

See image above for figure legend
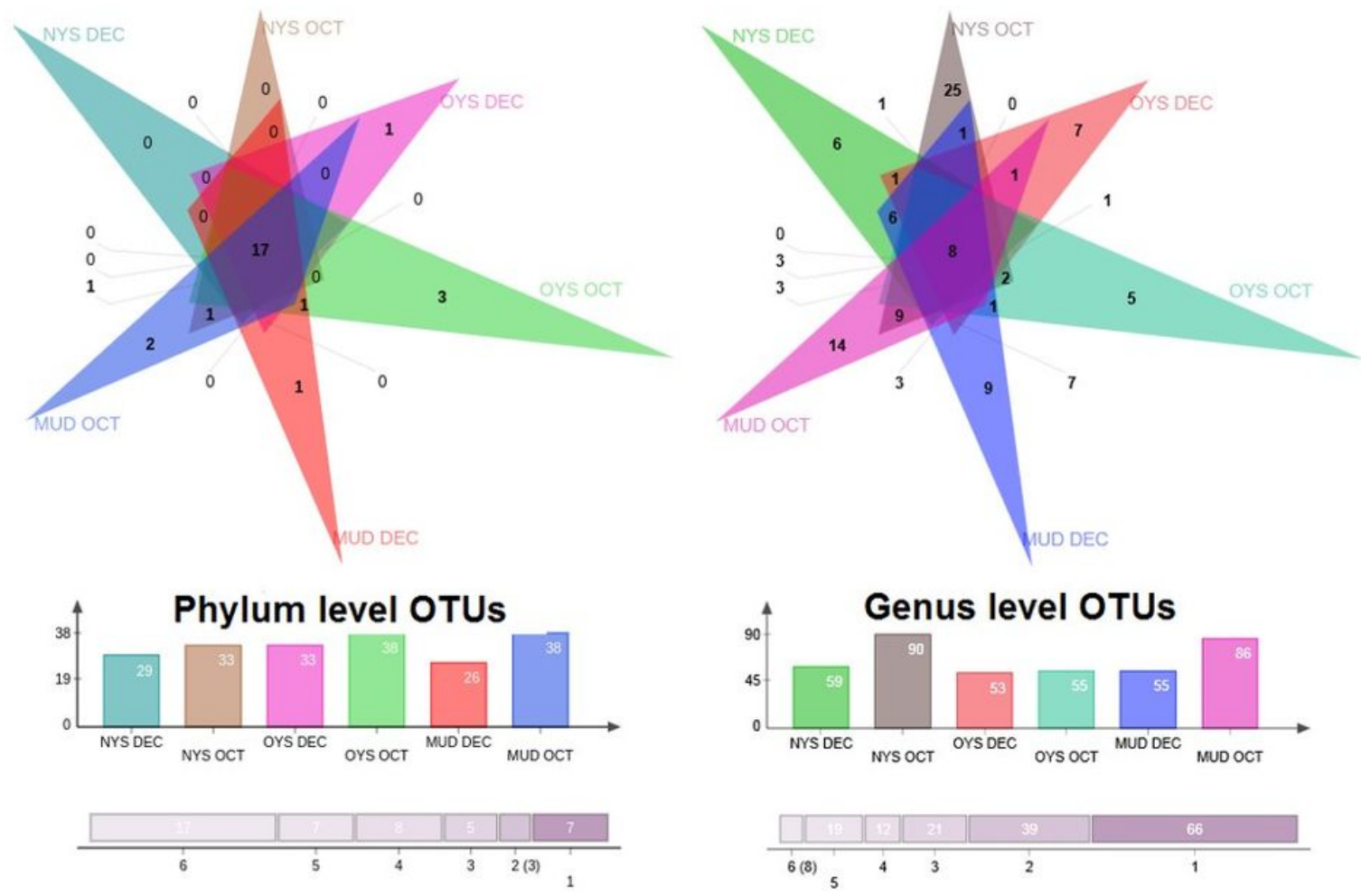

Figure 5: Comparison of distribution of OTUs across phylum and genus level.

Figure 5

See image above for figure legend 


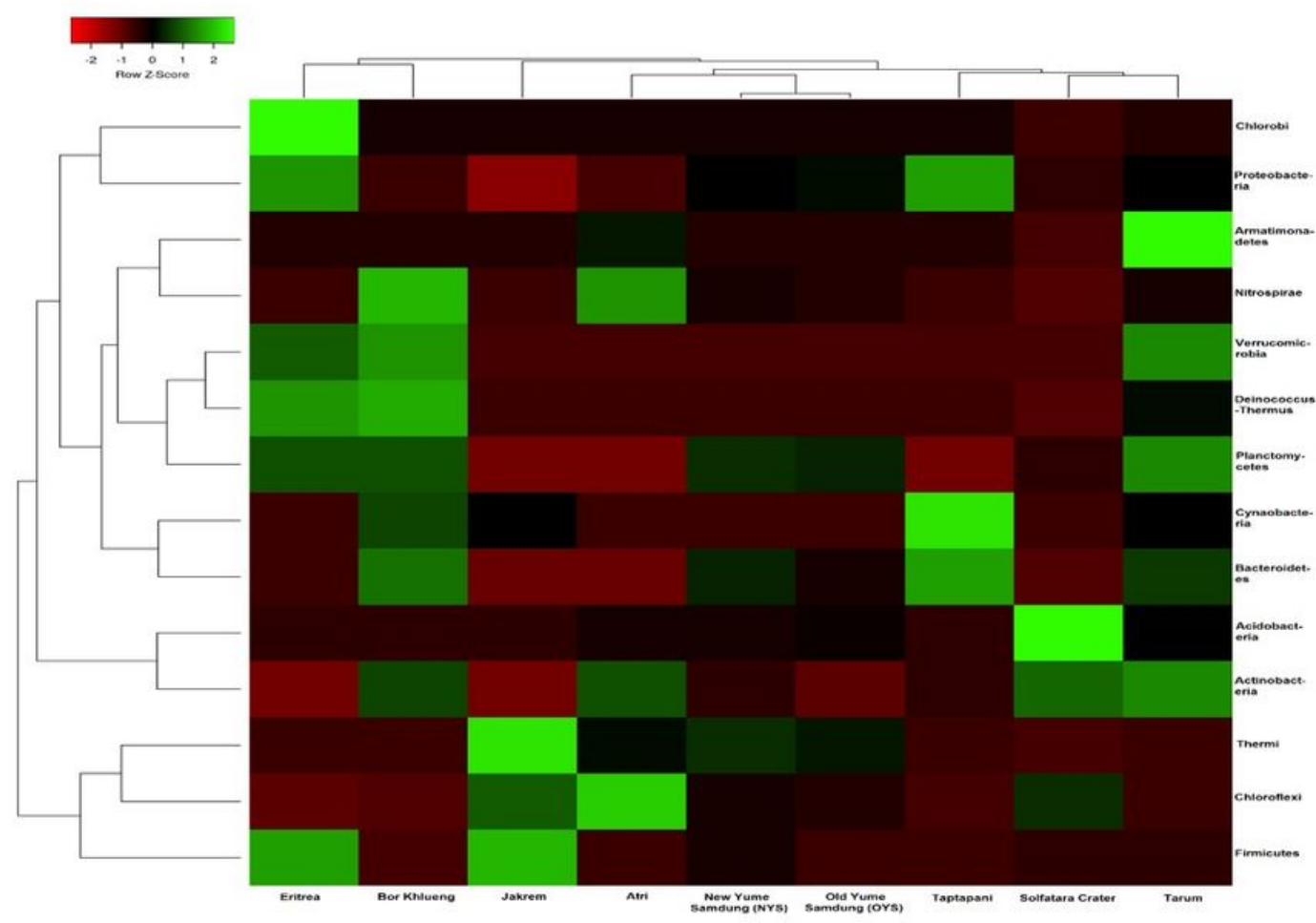

Figure 6: Comparison of the bacterial diversity present in the hot spring mud sediments globally.

\section{Figure 6}

See image above for figure legend

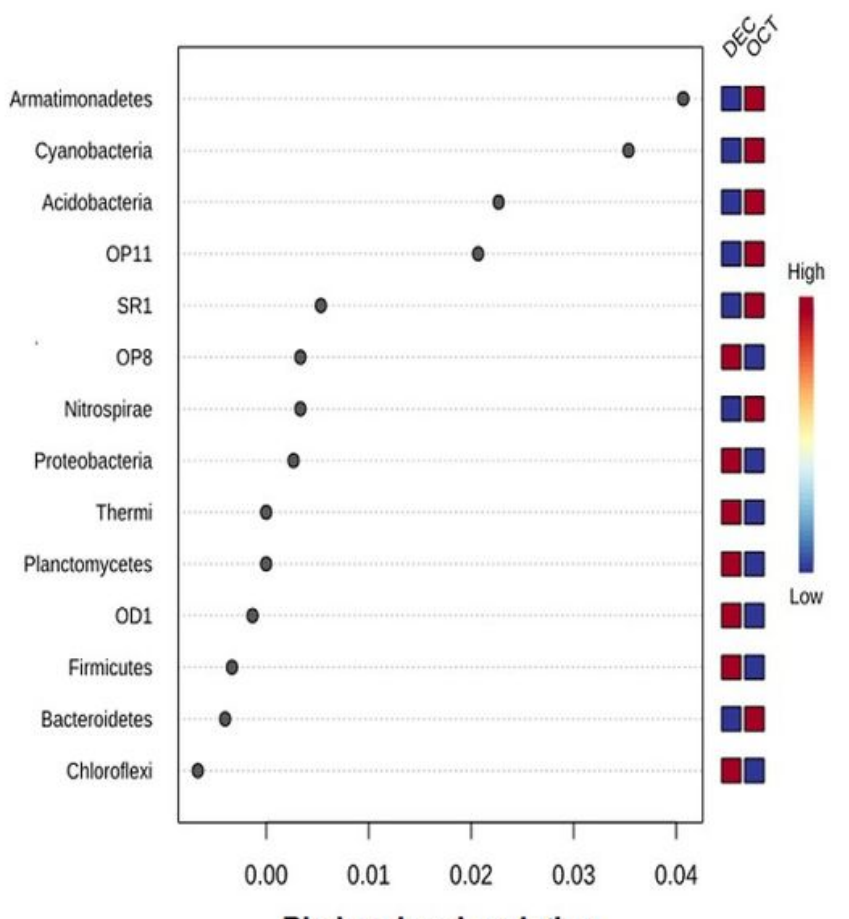

Phylum level variation

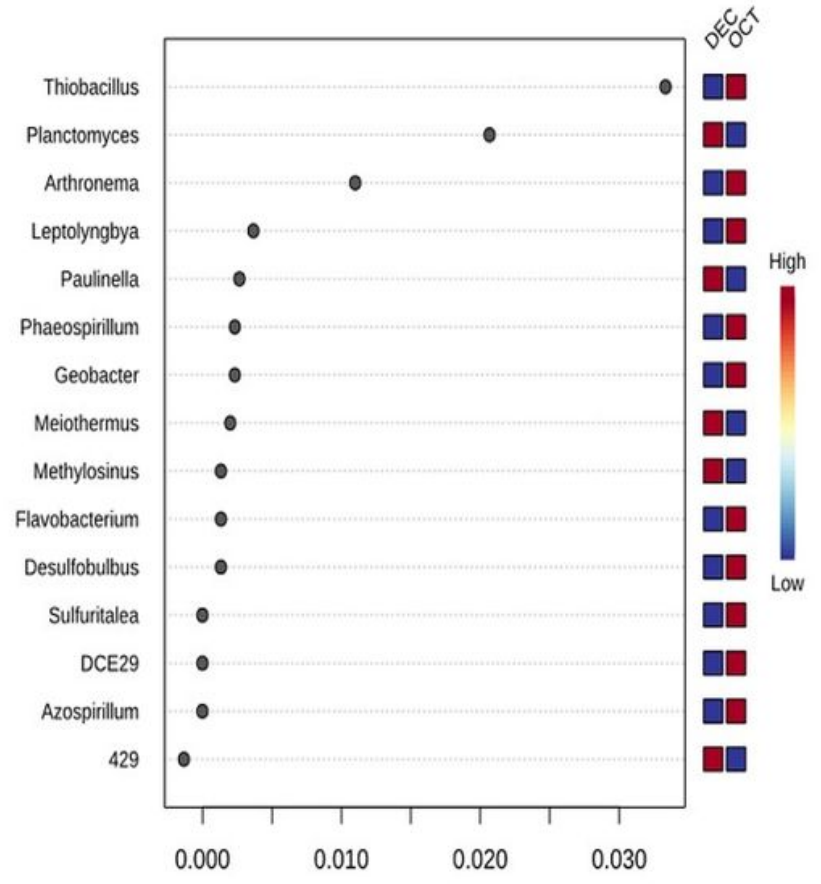

Genus level variation

Figure 7: Fluctuations observed at phylum and genus level during the month variation of the post-monsoon season.

Figure 7 
See image above for figure legend

\section{Supplementary Files}

This is a list of supplementary files associated with this preprint. Click to download.

- SupplementaryFigures.docx

- SupplementaryTables.docx 